\title{
"[M]ultitudinous and Minute": Early Twentieth-Century Scientific, Literary and Psychological Representations of the Mass
}

\section{Rachel Crossland}

During his annus mirabilis of 1905, in addition to papers on the special theory of relativity and the quantum nature of light, Albert Einstein published a revolutionary paper on Brownian motion, following this up with four further papers on the subject over the following three years. Einstein's work in this area paved the way for the acceptance of the physical reality of atomic and molecular models, and can be seen as one of the most significant moments in the physical investigation of large numbers of molecules, an area of study which had come to the fore in the mid-nineteenth century. Physics was not the only field to be struggling with issues relating to large masses during this period: indeed, the emergence of social statistics in nineteenth-century France had already had a direct impact on scientific approaches to the mass (Porter 114). The ongoing social, cultural and political implications of such ideas outside of the purely scientific realm became particularly evident with Gustave Le Bon's 1895 declaration that "The age we are about to enter will in truth be the ERA OF CROWDS" (xv). In turn, the urban focus of much modernist literature, and in particular its emphasis on the place of the individual within city crowds, stresses the resonance of such issues across traditional disciplinary divides. This article will consider the ways in which the disciplines of molecular physics, crowd psychology and modernist literature (represented here by the writings of Virginia Woolf) both overlapped with and drew directly on each other in their engagements with and treatments of large-scale populations, whether of particles, human beings or fictional characters. Moreover, it will show how, in N. Katherine Hayles's terms, each discipline was drawn to focus on this problem because the "concerns" underlying it were "highly charged within a prevailing cultural context" (xi), a context which comprised rapid population growth and mass urbanisation, and which raised the question of the nature of the relationship between the individual and the mass.

Brownian motion is the name given to the movement exhibited by microscopic particles suspended in a medium made up of molecules of much smaller size and mass: in current GCSE science the examples most frequently used are pollen grains in water and smoke particles in air. Observed through a microscope, the individual pollen or smoke particles are each seen to be moving almost constantly in a random and "wholly haphazard" manner (Perrin, Atoms 83). However, as the Scottish botanist Robert Brown, after whom the phenomenon is named, proved in the $1820 \mathrm{~s}$, this motion is due not to living organisms, but rather "belong[s] to the particle itself" 
("Brief Account" 338), thus making it a question for physics rather than biology (Brush 3).

Nearly one hundred years after Brown's work, Jean Perrin wrote that "the most striking feature of the Brownian movement is the absolute independence of the displacements of neighbouring particles, so near together that they pass by one another" (Brownian Movement 5), and indeed Brown himself was "unable to account" for the movements he observed ("Additional Remarks" 315). However, James Clerk Maxwell's development of the kinetic theory of gases in the 1860s and 1870s provided a possible explanation: Maxwell's model focuses on the movements, interactions and collisions of individual molecules, and scientists were soon looking to these molecular collisions to explain Brownian motion. Yet there were a number of problems with this idea: firstly, the molecular hypothesis was not universally accepted as a physical reality in the nineteenth century; and secondly, it did not seem possible that, if they existed, minuscule molecules could be responsible for the movements of comparatively massive particles. Indeed, in 1879 the botanist Karl von Nägeli highlighted what he considered to be the ridiculous nature of the molecular model of Brownian motion by showing that "a million water molecules must strike the starch particles (Stärkekörnchen) at the same moment and from the same direction in order to explain the single jerk of the Brownian granule" (M. Nye 26).

In tackling this ongoing problem in 1905, Einstein used the molecular hypothesis to explain Brownian motion through reference to molecular collisions, but added a key and radical insight: fluctuations in the medium mean that a number of molecules suddenly collide with a particle at the same time and in the same direction, thus causing it to move in that direction (Rigden 63-4). ${ }^{1}$ This is the model rejected as ridiculous by Nägeli, but Einstein's addition of random fluctuations within the medium means that such an occurrence is by no means as unlikely or as preposterous as Nägeli had imagined. In addition, it helps to explain what Perrin called "the most striking feature of the Brownian movement": "the motions of the individual particles are mutually independent" (Einstein 132) because each is acted on by a different set of molecules moving according to a distinct fluctuation. While such a model highlights the independent movements of individual particles, Einstein, unlike other scientists working on Brownian motion during the same period, focused on "a probability distribution" rather than the "life history" of one or more particles (M. Nye 112). Einstein's explanation of, and accompanying formula for, Brownian motion sparked a wave of experimental interest, and was proved in 1908 by Perrin, notably through a close focus on the movements of a small number of individual particles, (Fig. 1). Perrin's results, and his explanations thereof, were very successful within the scientific community: they were translated "almost immediately" (M. Nye 148), with his 1909 work Brownian Movement and Molecular Reality appearing in English as early as 1910 in a translation by the noted physical chemist Frederick Soddy. Perrin went on to win the Nobel Prize in Physics in 1926 for his work on the physical reality of atoms, within which his experiments on Brownian motion played a vital part: as Perrin himself wrote in 1909, "the molecular theory of the Brownian movement can be regarded as experimentally established, and, at the same time, it becomes very difficult to deny the objective reality of molecules" (Brownian Movement 46).

The movement towards a model involving random fluctuations and probability distributions necessitates an obvious turn towards statistical measures, but while such an approach may have been relatively new to physics at the turn of the century, the same certainly cannot be said of studies within what we now call the social sciences. Indeed, it was the nineteenth century which saw the emergence and increasing 
influence of the field of social statistics, a discipline which "begins by conceding that individual humans are too complex and diverse to serve as the basis of science, and has recourse instead to numerical frequencies as its elemental data" (Gigerenzer et al. 42). This realisation, and the practical applications thereof, had a significant impact on a particularly important nineteenth-century scientist who we have already had cause to mention: Maxwell. As David Bodanis explains, "it was by explicit acknowledgement to [social statistics] that Maxwell worked out his theory of gases where the scurrying molecules also were described only by overall statistics, and not individual biographies" (19).

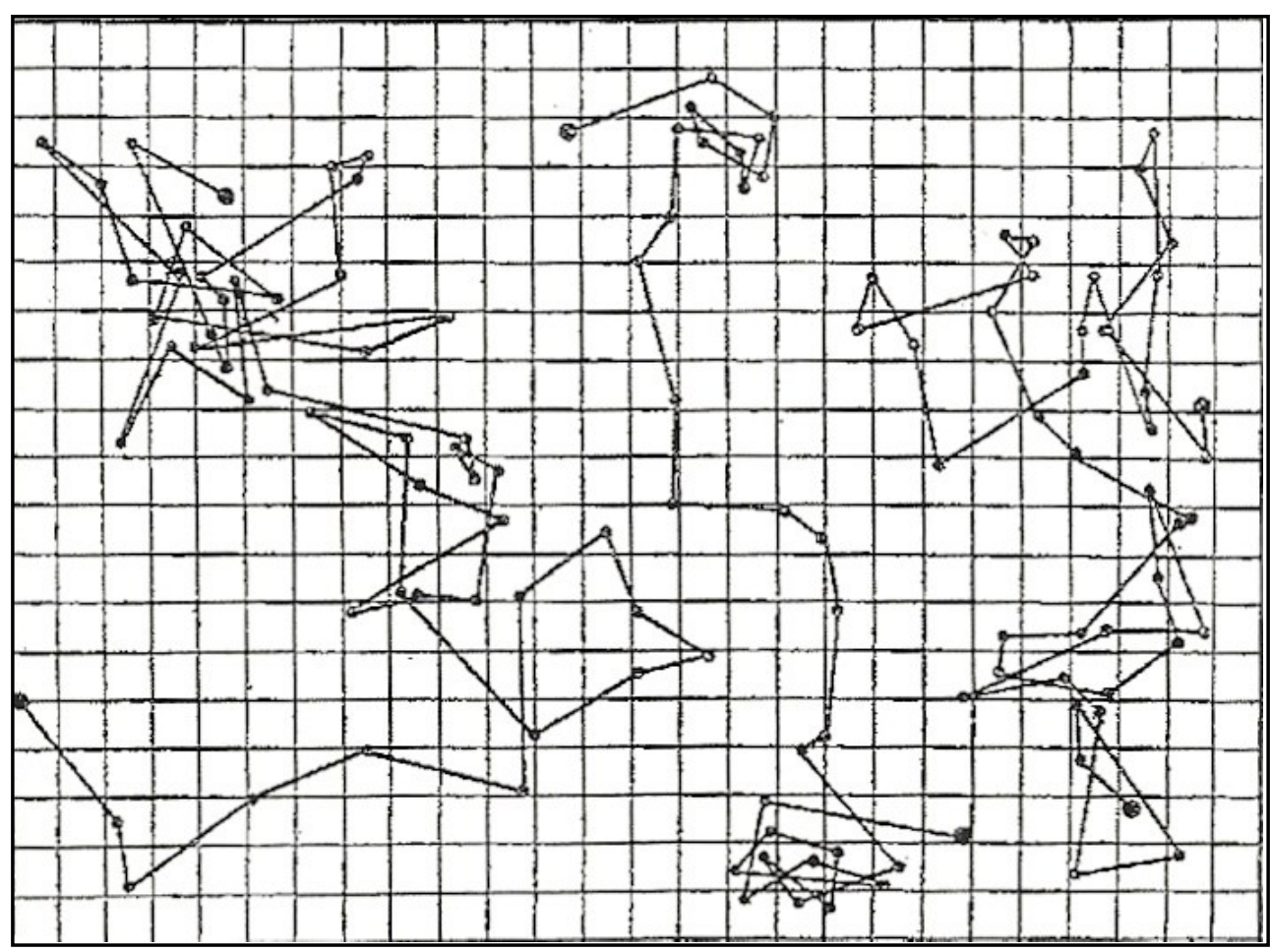

Fig. 1.

Brownian motion in action: "three drawings obtained by tracing the segments which join the consecutive positions of the same granules of mastic at intervals of thirty seconds"

Perrin, Brownian Movement 63-4, Shelfmark 193952 e.72. The Bodleian

Library, University of Oxford. Reprinted with kind permission.

This explicit acknowledgement on Maxwell's part comes in a lecture that he delivered to the British Association in 1873, and which was subsequently published in Nature:

As long as we have to deal with only two molecules, and have all the data given us, we can calculate the result of their encounter, but when we have to deal with millions of molecules, each of which has millions of encounters in a second, the complexity of he [sic] problem seems to shut out all hope of a legitimate solution.

The modern atomists have therefore adopted a method which is I believe new in the department of mathematical physics, though it has long been in use in the Section of Statistics. (440) 
Statistics thus entered into physics, and the relevance of this development thirty years later to Einstein and other theorists of Brownian motion is clear. ${ }^{2}$

Theodore Porter has described the links between nineteenth-century physics and statistics as forming "an interdisciplinary matrix," tracing models from statistical astronomy into social statistics and from social statistics into molecular physics (114). However, it is possible to extend such a matrix further by considering what Hayles calls the underlying "highly charged" concerns of the "prevailing cultural context" (xi) which encouraged, even necessitated, the emergence of social statistics as a discipline in its own right. Among such concerns, a rapidly expanding population is clearly a significant factor; the population of England and Wales alone more than doubled between 1841 and 1901, while the urban population in particular was growing at an unprecedented rate: "Towns of over 100,000 inhabitants increased from six in 1841 to thirty in 1901 - only London had been so large in 1801" (Banks 105). Nor was such growth limited to this country, with eleven cities of over one million inhabitants having emerged worldwide by 1900 (Bullock 59). Moreover, this was an increasingly organised population, the working-class section in particular (Bullock 61), which meant, to expand the interdisciplinary matrix yet further, that an understanding of crowd psychology rapidly became an urgent concern for those in government and other positions of responsibility in the early part of the twentieth century.

Gustave Le Bon is widely regarded as the most important, and "most popular" (R. Nye 167), proponent of a theory of the crowd, his ideas retaining their relevance even today, more than one hundred years after the publication of his highly significant 1895 work, La Psychologie des foules.

Le Bon's interest is not merely aimed at the crowd as a random gathering together of various completely unrelated people, however, but rather at what he calls the organised, or psychological, crowd:

Under certain given circumstances, and only under those circumstances, an agglomeration of men presents new characteristics very different from those of the individuals composing it. The sentiments and ideas of all the persons in the gathering take one and the same direction, and their conscious personality vanishes. A collective mind is formed, doubtless transitory, but presenting very clearly defined characteristics. The gathering has thus become what, in the absence of a better expression, I will call an organised crowd, or, if the term is considered preferable, a psychological crowd. It forms a single being, and is subjected to the law of the mental unity of crowds. (2)

Le Bon was not alone in suggesting such a different side to the crowd. In 1920 William McDougall explained the difference between a "mass of human beings" and "a crowd in the psychological sense of the word" particularly clearly:

There is a dense gathering of several hundred individuals at the Mansion House Crossing at noon of every week-day; but ordinarily each of them is bent upon his own task, pursues his own ends, paying little or no regard to those about him. But let a fire-engine come galloping through the throng of traffic, or the Lord Mayor's state coach arrive, and instantly the concourse assumes in some degree the character of a psychological crowd. All eyes are 
turned upon the fire-engine or coach; the attention of all is directed to the same object; all experience in some degree the same emotion, and the state of mind of each person is in some degree affected by the mental processes of all those about him. Those are the fundamental conditions of collective mental life. (22-3)

For any reader of Virginia Woolf the most striking thing about the passage above is its similarity to certain moments in Mrs Dalloway, published just five years later. The early scenes involving the motor car and the aeroplane are particularly reminiscent of McDougall's description of a psychological crowd: in the former, "Every one looked at the motor car" (16), just as "the attention of all is directed to the same object" in McDougall. Meanwhile, we see that "all experience in some degree the same emotion," even though only for "thirty seconds." as "in all the hat shops and tailors' shops strangers looked at each other and thought of the dead; of the flag; of Empire" (19). This universally fixed attention on the motor car is preserved until the aeroplane appears, at which point "Every one looked up" (22): the attention of the crowd is shifted from the question "Whose face was it?" (15) to another question, "what word was it writing?" (23). As Gillian Beer emphasises, "Each person reads the plane's message differently," but "The message does not matter; the communal act of sky-gazing does" (161). Both incidents involve the formation of a psychological crowd as defined by McDougall, but interestingly, despite her inclusion in the first psychological crowd, Mrs Dalloway herself remains separate from the second, asking Lucy on her arrival back home not what word the aeroplane has written, but "What are they looking at?" (31) [my emphasis].

While Mrs Dalloway presents us with a number of examples of the formation of a psychological crowd, Night and Day, published one year before McDougall's study in 1919, provides instead a repeated focus on what McDougall calls the "mass of human beings." Towards the end of this novel, Katharine seeks Ralph among the rush-hour commuters around Lincoln's Inn Fields, picturing the crowd as "tend[ing] the enormous rush of the current - the great flow, the deep stream, the unquenchable tide" (374). Despite the sense here that everyone is moving in the same direction, there is no indication that the individuals within this crowd are pursuing anything other than their own ends; indeed, it is Katharine's pursuit of her own ends that forces these other individuals to appear, both for her and for the reader, as "two currents" (374): "More and more plainly did she see him [Ralph]; and more and more did he seem to her unlike any one else" (375). In a more chaotic version of a similar scene, although one in which reference is still made to "Streams of people," the protagonist of Orlando (1928) is confronted by the confusing multiplicity of the streets of London:

She looked anxiously at people's faces. But that confused her still more. Here would come by a man sunk in despair, muttering to himself as if he knew some terrible sorrow. Past him would nudge a fat, jolly-faced fellow, shouldering his way along as if it were a festival for all the world. Indeed, she came to the conclusion that there was neither rhyme nor reason in any of it. Each man and each woman was bent on his own affairs. And where was she to go? (191)

This scene provides a particularly clear example of McDougall's non-psychological crowd, and the verbal similarity between Woolf's penultimate sentence above and 
McDougall's phrase "each of them is bent upon his own task" is surely significant; whether Woolf knew McDougall's work directly is unknown, although she did engage with other contemporary texts on crowd psychology.

It is interesting to note that these two different ways of approaching and representing the crowd, either as a "mass of human beings" or as a psychological crowd, seem to be mirrored in Perrin's explanation of the difference between Brownian motion and other particulate movement, in this case that of dust:

It is easy to see that the neighbouring dust-particles move in general in the same sense, roughly tracing out the form of the common current which bears them along, whereas the most striking feature of the Brownian movement is the absolute independence of the displacements of neighbouring particles, so near together that they pass by one another. (Brownian Movement 5)

Brownian particles thus resemble McDougall's non-psychological crowd, in which the individual "is bent upon his own task, pursues his own ends, paying little or no regard to those about him," much like Katharine in Night and Day. In contrast, individuals in a psychological crowd behave, in Le Bon's words, like "a grain of sand amid other grains of sand, which the wind stirs up at will" (13); they respond collectively to the same stimulus, as do the characters united in moments of visual spectacle and speculation in Mrs Dalloway.

While the apparent parallel between Perrin's writings on Brownian motion and the writings of crowd psychologists like McDougall and Le Bon may be no more than coincidence, the emerging discipline of crowd psychology certainly did make use of scientific ideas, language and analogies. It is worth noting before considering such examples, however, that there was already a precedent for the use of physical, scientific language in the depiction of crowds. Peter Nicholls has drawn attention to an insightful scientific image of the crowd, and an "increasingly popular metaphor" (16), in a paper by John Ruskin on "The Study of Architecture in Our Schools" which Ruskin read to the Royal Institute of British Architects in 1865: Ruskin envisages the crowd as "a tormented mob" in which "every creature is only one atom in a drift of human dust, and current of interchanging particles" (24). Such an image may remind us of Le Bon's "grain of sand amid other grains of sand, which the wind stirs up at will," but with its vocabulary of atoms in relation to particles and currents it is clearly possible to suggest a scientific link here, especially via the consideration that, according to Perrin, many early observers of Brownian motion "thought it analogous to the movement of the dust particles" (Brownian Movement 3). Friedrich Engels had also described modern urban life as "the world of atoms" in the 1840s (37), while the journalist W. E. Adams published his Memoirs of a Social Atom in 1903, stressing his choice of term as indicating his "insignificance" and describing himself as "a small speck on the surface of society" (xiii).

In the foundational texts of crowd psychology, scientific discourse is employed in a slightly different way and with a somewhat different purpose; that of legitimising the new discipline as scientific, as Deborah Parsons explains: "To emphasise the role of crowd psychology as a 'scientific' discipline, theorists employed terminology from other discourses such as medicine and evolutionary science" (44). Such examples are easy to find, especially in Le Bon's writing: for example, Le Bon describes how "the cells which constitute a living body form by their reunion a new being which displays characteristics very different from those possessed by each of 
the cells singly" in order to explain that the individuals in a psychological crowd present new characteristics simply by being joined in a crowd (6). Likewise, in Instincts of the Herd in Peace and War (1916), Wilfred Trotter describes the socialised gregariousness of the hive as "like a new creature," adding that "The hive and the ant's nest stand to the flock and the pack as the fully organised multicellular animal stands to the primitive zoogloea which is its forerunner" (166-7). Alternatively, returning to Le Bon, the same idea can be explained with recourse to chemistry, where "certain elements, when brought into contact - bases and acids, for example - combine to form a new body possessing properties quite different from those of the bodies that have served to form it" (7). Examples of this kind suggest that crowd psychologists found in previous scientific work both inspiration for their own ideas and a means by which to reinforce and legitimise them when making them public.

While the employment of scientific language and imagery as a means of implying scientific validity for a new discipline is perhaps not surprising, it is noteworthy that scientific explanations of molecular movements at the turn of the century often drew on images and models of human crowds. Maxwell himself used such an image in his 1873 lecture on "Molecules" in order to describe the difference between diffusion in a gas and in a liquid:

In a liquid the diffusion of motion from one molecule to another takes place much more rapidly than the diffusion of the molecules themselves, for the same reason that it is more expeditious in a dense crowd to pass on a letter from hand to hand than to give it to a special messenger to work his way through the crowd. (439)

Similarly, Karl Pearson used the notion of the crowd as a means of explaining the discontinuous nature of matter in The Grammar of Science (1892):

A crowd of human beings seen from a great height may look like a turbulent fluid in motion at every point. But we know from experience that this motion is only possible because there is some void in the crowd. It may become so densely packed that motion is no longer practicable. Thus it is with that relative motion of the parts of bodies upon which so much of modern physics depends; absolutely close packing, that is continuity, seems to render it impossible. (202)

Metaphors of this kind provide scientists like Maxwell and Pearson with a rhetorical device with which to help their readers to understand and visualise the scientific theories under discussion, but they also, as in the examples of scientific imagery in crowd psychology, provide a means of persuading readers of the validity of these theories, in this case legitimising scientific ideas through reference to everyday experiences.

There is one further implication to consider here as part of the expanding interdisciplinary matrix, however: images of the crowd, familiar to both scientists and readers alike, suggest that such everyday experiences may themselves have influenced contemporary approaches to specific scientific questions; after all, as Bodanis writes, when formulating a scientific theory "what better place to get fresh ideas than to just look around you?" (18). Bodanis's exploration of the relationship between scientific ideas and social context focuses on Louis Pasteur: "The language of Pasteur and 
conservatives generally against the masses of the people was almost exactly like the language Pasteur had developed to use against bacteria" (17). While Bodanis seems to be suggesting that Pasteur's science influenced his social analysis, he later reverses this apparent precedence by explaining that Pasteur's "fear of the mob" may in fact have come first (17): Bodanis draws attention to the extreme population growth which we have already considered, before stating that "One would not need to have been M. Pasteur to be attuned to swarming masses with that going on" (20-21). This article's explorations of Maxwell and other physicists, Le Bon and other crowd psychologists, and modernist writers like Woolf serve to emphasise Bodanis's point, and marks a return to Hayles's idea that "Different disciplines are drawn to similar problems because the concerns underlying them are highly charged within a prevailing cultural context" (xi).

While models which focus on a particular cultural context or interdisciplinary matrix are useful and important in studies which seek to work across traditional disciplinary divides, possible instances of direct influence remain relevant and should not be neglected. Woolf's direct engagement with the emerging discipline of crowd psychology can be traced through her diaries in particular, where we find her reading "Freud on Groups" in December 1939 (5: 252). The Woolfs also owned a copy of Trotter's Instincts of the Herd (see: Catalogue), which Leonard Woolf described as "exceedingly original" in his review for The New Statesman (327). Indeed, Leonard Woolf's statement that Trotter's "is not the ordinary beaten track of the writer on herd instinct and crowd psychology" (328) suggests the extent to which such works and ideas were familiar to both Leonard and his readers by 1916. Virginia Woolf also internalised, to some extent at least, Trotter's ideas: writing in her diary in 1917 she reports Roger Fry's "gloomy view, not of our life, but of the world's future," adding "but I think I detected the influence of Trotter \& the herd, \& so I distrusted him" (1: $80)$. However, she continues with a somewhat different tone:

Still, stepping out into Charlotte Street, where the Bloomsbury murder took place a week or two ago, \& seeing a crowd swarming in the road \& hearing women abuse each other $\&$ at the noise others come running with delight all this sordidity made me think him rather likely to be right. (1:80)

Allen McLaurin points out that in general the Bloomsbury group "interpreted the herd theory in a much more pessimistic sense than Trotter intended" (37), but even so, Trotter's ideas seem to have had a resonance for Woolf and her circle, affecting the ways in which they observed and interacted with their urban surroundings.

Perhaps unsurprisingly, Woolf's awareness of contemporary scientific ideas on molecular movements is harder to trace. However, images like those used by Maxwell and Pearson were also available in popular scientific texts which writers like Woolf are more likely to have known directly. Writing in The Cornhill Magazine in the early years of the twentieth century, the schoolteacher and Fellow of the Royal Society W. A. Shenstone explained the molecular make-up of a liquid in terms that are very similar to Pearson's above: "close packing would cause molecules to jostle one another, like people in a panic-stricken crowd in the street who have ceased to observe the rules of the road" ("Matter, Motion, and Molecules" 71-2). Shenstone's focus here on "a panic-stricken crowd" suggests a possible link to contemporary ideas of the crowd as a dangerous and unpredictable force, as expressed by Le Bon in particular (see: xix). In another article published during the same year, Shenstone describes liquid molecules as "like a man in a crowd, [. . .] constantly impeded by its 
neighbours" ("About Solutions" 327), an image which again frames the crowd as something of a negative force. The importance for popular science writers like Shenstone of such recognisable and familiar images is emphasised in some of the ideas which he was trying to explain to his non-specialist readers: thus he describes molecules of hydrogen as "so small that about sixty million million million of them will go inside a lady's thimble," and adds that they move "not sluggishly, like dust in the air, but at the rate of seventy miles a minute, so that every molecule comes into collision with some other molecule about eighteen thousand million times in every second of its existence" ("Matter, Motion, and Molecules" 72). Such extraordinarily large numbers and such tiny particles are very difficult to imagine, so the familiar handles of a thimble, dust particles and a man in a crowd play a vital role in enabling the reader to follow the scientific ideas explored in texts of this kind.

Virginia Woolf's links to The Cornhill Magazine, at first through her father, Leslie Stephen, who was its editor from 1871 to 1882 (although he wrote for the magazine from 1866 to 1883) (see: Maurer), and later through her own contributions to its pages in 1908, are well known, and it is thus possible to speculate about her reading its popular science articles, of which Shenstone was the main contributor from 1903 onwards. However, Woolf (at the time still Virginia Stephen) and Shenstone (who died early in 1908) never published articles in the same issue of The Cornhill Magazine, thus making it impossible to say with any certainty that Woolf would have known Shenstone's work.

Like many modernist writers, Woolf uses the modern city, especially London, as the setting for a large proportion of her fictional and non-fictional texts, but even among her contemporaries Woolf seems to have a particularly clear grasp of and feel for the rhythms, movement and liveliness, what she calls the "perpetual race and disorder" (Essays 284), which such urban settings entail. One aspect of Woolf's portrayal of crowd and city scenes is her focus on their physical, even violent, nature: in a diary entry about walking home along Oxford Street in 1930, Woolf describes how "People fight \& struggle. Knocking each other off the pavement" (Diary 3: 298), while more than ten years earlier, in 1918, she had written of the "jerks \& spasms" of London (Diary 1: 95). Meanwhile, in The Years (1937) "People jostled and hustled and [Eleanor] quickened her pace in time with theirs" (82), while later Crosby pauses to rest before she goes on "to do battle with the crowd of shoppers in the High Street" where she will "have to shove and push, and be jostled this way and that" (222). In Flush (1933), on their arrival in Italy, "Flush leapt and jumped this way and that, and so did Wilson" as "They were forced on and off the pavement twenty times, to avoid a cart, a bullock, a troop of soldiers, a drove of goats" (65); and in "Abbeys and Cathedrals" (1932) the problem of sustaining a line of reasoned thought under such circumstances is emphasised as Woolf breaks off to reflect "how we jostle and skip and circumvent each other in the street, how sharply we cut corners, how nimbly we skip beneath motor cars" (Essays 302).

The violent and shocking aspect of early twentieth-century city life has been discussed by a number of critics, both at the time and since. Thus, commenting on the quotation from Ruskin which we have already considered, Nicholls explains that city life "was not always just a matter of 'drift', for the new pace of life in the city made the streets [. . . ] a setting for violent collisions and confrontations" (16). Likewise, Walter Benjamin describes city life as "involv[ing] the individual in a series of shocks and collisions" (132), and these descriptions may well remind us of the molecular collisions at the heart of early twentieth-century discussions of both particulate movement in general and Brownian motion in particular. Similarly, Marshall Berman, 
who, like Benjamin, is writing about the poetry of Charles Baudelaire, explores the "moving chaos" of the modern city street in some detail, explaining that it "lies not in the movers themselves - the individual walkers or drivers, each of whom may be pursuing the most efficient route for himself - but in their interaction, in the totality of their movements in a common space" (159). This leads to an interesting phenomenon:

In order to cross the moving chaos, he [the "man in the modern street"] must attune and adapt himself to its moves, must learn to not merely keep up with it but to stay at least a step ahead. He must become adept at soubresauts and mouvements brusques, at sudden, abrupt, jagged twists and shifts - and not only with his legs and his body, but with his mind and his sensibility as well. (Berman 159)

As such, in order to avoid the Brownian-esque collisions that the modern city threatens, Berman's modern man has to pre-empt them; yet such avoidance means that he still exhibits an equivalent spasmodic pattern of movement.

As discussed, Brownian motion is caused by the collisions of the molecules of a particular medium with the larger particles of a substance suspended within that medium. Woolf herself makes frequent reference when writing about cities and crowds to some kind of medium, most often one which is liquid in form as in "the current - the great flow, the deep stream, the unquenchable tide" in Night and Day, or her essay "Oxford Street Tide" (1932) which describes "the bounding, careless, remorseless tide of the street" (Essays 287). According to Gabriel Tarde, images involving a liquid medium "naturally come to mind every time we speak of crowds as well as publics" as both are "like streams with a poorly defined channel" (278). Similarly, Georg Simmel in "The Metropolis and Mental Life" (1903) describes the "stimulations, interests, uses of time and consciousness" of life in the metropolis as like a "stream" in which "one needs hardly to swim for oneself" (422). Interestingly in relation to Brownian motion and other examples of violent collisions, Simmel also speaks of the difficulty of maintaining one's individual personality under the "impact" of so many and such varied stimulations (422).

The idea that Brownian motion may provide a way in which to visualise, and even to understand, crowd behaviour has been suggested most directly by the historian of crowd psychology Serge Moscovici: "The crowd is filled with hundreds of incessant movements like those of particles suspended in a liquid and is perpetually milling and agitated" (274). However, although this model does seem to have some relevance to the ideas discussed here, it is important to note that it has not been elaborated fully and that, in particular, Moscovici offers no comment on the nature of the liquid medium which surrounds and influences the human particles of the crowd. It is not clear whether Moscovici means for the medium to be something abstract, what Michael Tratner calls "the social medium" (9), or whether he simply has not thought through the implications of the scientific model which he is employing here. Either way it is clear that to be of any wider use this model needs to be developed, expanded and explained, and that will be the focus of the remainder of this article.

One of Woolf's favourite images for crowd and city scenes is the item of debris being swept onwards by a stream: in The Waves (1931) Louis reflects "We are drawn through the booking-office on to the platform as a stream draws twigs and straws round the piers of a bridge" (21), while in The Years Charing Cross station is repeatedly described in similar terms, as "People on foot, people in cabs were being sucked in like straws round the piers of a bridge" (82; see also: 84,172$){ }^{3}$ As in 
Moscovici's formulation, there is no indication as to the nature of the fluid medium here, yet it seems likely that it represents the wider, more generalised, crowd. Such an assessment is reinforced by a return to the passages from Night and Day already considered: Katharine pictures the crowd of commuters around her as "tend[ing] the enormous rush of the current - the great flow, the deep stream, the unquenchable tide" and as "two currents" (374), thus envisaging the crowd itself as a fluid medium.

Although, as Tarde suggests, the use of fluid metaphors to describe crowds may be seen as somewhat commonplace, Woolf's employment of such metaphors is significant due to her contrasting focus on distinct, non-fluid, individuals within the liquid medium. In Night and Day Katharine remains separate from the liquid crowd she perceives around her, as emphasised by Woolf's description of Katharine as a "spectator"; there is only one short moment during which Katharine is almost overwhelmed by and "absorbed" into the surrounding crowd, but in that instant her recollection of the individual figure of Ralph calls her back to herself: "Suddenly she was clutched, unwilling, from the outside, by the recollection of her purpose in coming there. She had come to find Ralph Denham" (374). Earlier in the novel, looking out of the window of an inn over the streets of Lincoln, Ralph had himself experienced a similar moment of revelation, as Katharine appeared among the crowd below which "seemed to him only a dissolving and combining pattern of black particles":

He was about to turn and ask the waiter to bring the bill, when his eye was caught by a tall figure walking quickly along the opposite pavement - a tall figure, upright, dark, and commanding, much detached from her surroundings. (193)

In both of these examples from Night and Day Woolf imagines an individual character as distinct and separate from a surrounding mass of other human beings. In addition, in the former example Katharine's focus on finding Ralph among the crowd enables her to see him "More and more plainly" as well as to recognise that "more and more did he seem to her unlike any one else" (375). Might it be possible, then, to approach individual fictional characters like Katharine and Ralph as if they were particles suspended in a medium like those which exhibit Brownian motion? And to what extent is this justifiable when both characters and medium ultimately consist of the same thing, that is, human beings?

In seeking to answer such questions it is worth considering an image employed by Jinny in The Waves: "I am going to push out into the heterogeneous crowd. I am going to be buffeted; to be flung up, and flung down, among men, like a ship on the sea" (134). In this image Jinny is the ship while the surrounding mass of the crowd, gendered specifically as male, seems to represent the sea. This description of an individual within a crowd resonates with one of the images used by Perrin to describe Brownian motion:

Direct perception of the molecules in agitation is not possible, for the same reason that the motion of the waves is not noticed by an observer at too great a distance from them. But if a ship comes in sight, he will be able to see that it is rocking, which will enable him to infer the existence of a possibly unsuspected motion of the sea's surface. (Atoms 83) 
Like Jinny, Brownian particles are "buffeted" by the surrounding mass but, as in The Waves, this medium remains indistinct, visible only through its effect on the particles being observed.

In her late autobiographical piece "Sketch of the Past" (written 1939-40), Woolf discusses "the invisible presences who after all play so important a part in every life," adding "I see myself as a fish in a stream; deflected; held in place; but cannot describe the stream" (Moments of Being 92). Tratner has argued that the depiction of this "invisible stream" was modernism's "peculiar task," and that a character in modernist fiction "is only a phenomenon whose movements, like those of a fish, are there to reveal the action of 'the stream', the social medium" (9). While there is certainly something in this idea, Tratner's "only" is too forceful: despite the obvious importance of crowds and masses to modern literary expressions of the city, and despite the key role played by changing social forces in Woolf's works, in particular those which cover an extended period like The Years and Orlando, it is clear that within such novels individual characters remain distinct and all-important for the reader - the very titles of Mrs Dalloway and Orlando emphasise this, while even in The Waves the reader is able to hold on to the six individuals as distinct, at least at certain moments within the narrative. A similar conflict between the individual and the mass can be found in both investigations of Brownian motion, explained in terms of probabilities by Einstein but proved through experiments focusing on individual particles by Perrin, and crowd psychology, which has frequent recourse to the idea of a possible leader for the crowd. What matters most, then, for all these disciplines, is the relationship between the specific individual and the generalised mass.

Woolf emphasises the difference between the individual and the mass by portraying the former as distinct from and more significant than the latter. This is particularly noticeable in "Abbeys and Cathedrals" where Woolf explains that "men and women seem to have shrunk and become multitudinous and minute instead of single and substantial"; Woolf contrasts the individual figures of William Shakespeare and Ben Jonson with "a million Mr Smiths and Miss Browns," reflecting that the latter "seem too many, too minute, too like each other to have each a name, a character, a separate life of their own" (Essays 301), terms which may remind us of the nineteenth-century movement towards statistical representations of the masses. In contrast, the opening of The Voyage Out (1915) presents us with a couple in comparison with which "most people looked small," this majority being described as consisting of "small, agitated figures," an image which resonates particularly strongly with Brownian motion by portraying the individuals in question as more massive than the surrounding moving medium (3). Likewise, in Night and Day Ralph sees Katharine as bigger than the crowds massing around her, reflecting that she "look[s] as if the scurrying crowd impeded her, and her direction were different from theirs" (106). At moments like this the individuality of a character is defined in contrast to the generalised, indistinguishable mass: the undifferentiated medium facilitates the recognition of the uniqueness of the individual, for themselves, for other characters and for the reader. Indeed, the medium is almost exclusively significant in the passages from Night and Day for the way in which they privilege Katharine and Ralph as individuals. As such, both Katharine and Ralph remain more significant than the crowd which surrounds them within their urban settings, even though they still seem to remain subject in some way to the influences and effects of this surrounding medium. ${ }^{4}$ 
One final image from Night and Day may serve to emphasise this point particularly clearly: Katharine, reflecting on the relationships between herself, Ralph, Mary, William and Cassandra, describes this set of individuals as "the lantern-bearers, whose lights, scattered among the crowd, wove a pattern, dissolving, joining, meeting again in combination" (266). There is no suggestion in this passage that the crowd plays a direct part in the movements of the novel's protagonists - the crowd, indeed, remains indistinct, and undefined here - yet in light of the ideas of Brownian motion this passage suggests the place of these "lantern-bearers" within the wider medium of the crowd from which they can never escape. Such an interpretation is aided by a consideration of Perrin's diagram (Fig. 1.), a pattern which represents something very similar to that which Woolf is describing above.

The question of the relationship between the individual and the mass was an urgent one in the early twentieth century, provoked at least in part by a rapidly expanding and organised population and increasing urbanisation. The question manifested itself in a turn towards statistical measures and the development of crowd psychology, as well as in the depiction of urban masses in literary works alongside an ongoing focus on individual characters. As parts of the contemporary interdisciplinary matrix and prevailing cultural context, molecular physics, crowd psychology and modernist literature were each drawn to tackle this question from their own disciplinary standpoints. Moreover, each discipline interacted with the approaches of the others, either directly as in Maxwell's use of social statistics, or more generally as in the adoption of scientific discourse into crowd psychology. By considering these different disciplines together, it is possible to recover a sense of how the concerns underlying the problem of large masses were actually experienced at the time. Such work involves the reconstruction of a particular period's interdisciplinary matrix, or at least specific section parts of it, a task which is the central challenge, as well as the great reward, of all interdisciplinary work. 


\section{Notes}

1. It is worth noting that Einstein expressed some reservations as to whether the movement he discussed in his 1905 paper was actually Brownian motion (123).

2. In a more recent further development in this disciplinary interplay, the current study of crowd dynamics uses approaches drawn from statistical physics in order to model the crowd as "a many-particle system" (Schadschneider 22).

3. This image may have been suggested to Woolf by Desmond MacCarthy's dedicatory letter to Roger Fry in the first English translation of Jules Romains's The Death of a Nobody: "Individuality - character, the very pivot on which the art of the novelist has turned hitherto, is here made of no account. Individuals are as of little importance as wisps of straw riding down a river in flood-time, melting and dissolving as they pass, one straw going this way, one that" (vi-vii).

4. I have discussed elsewhere the relevance of these ideas to the figure of the flâneur in modernist literature, as well as the role of apparent fluctuations in fictional crowds (Crossland 257-66). 


\section{Works Cited}

Adams, W. E. Memoirs of a Social Atom. Vol. 1. London: Hutchinson, 1903.

Banks, J. A. "The Contagion of Numbers." The Victorian City: Images and Realities. Vol. 1. Ed. H. J. Dyos and Michael Wolff. London: Routledge, 1973. 105-22.

Beer, Gillian. Virginia Woolf: The Common Ground. Edinburgh: Edinburgh UP, 1996.

Benjamin, Walter. Charles Baudelaire: A Lyric Poet in the Era of High Capitalism. Trans. Harry Zohn. London: NLB, 1973.

Berman, Marshall. All That Is Solid Melts Into Air: The Experience of Modernity. London: Verso, 1983.

Bodanis, David. Web of Words: The Ideas behind Politics. Basingstoke: Macmillan, 1988.

Brown, Robert. "Additional Remarks on Active Molecules." The Edinburgh Journal of Science ns 1.2 (1829): 314-19.

---. "A Brief Account of Microscopical Observations on the Particles contained in the Pollen of Plants; and on the general Existence of Active Molecules in Organic and Inorganic Bodies." The Edinburgh Journal of Science 9.18 (1828): 33646.

Brush, Stephen G. "A History of Random Processes. I. Brownian Movement from Brown to Perrin." Archive for History of Exact Sciences 5.1 (1968): 1-36.

Bullock, Allan. "The Double Image." Modernism: A Guide to European Literature, 1890-1930. Ed. Malcolm Bradbury and James McFarlane. 1976. London: Penguin, 1991. 58-70.

Catalogue of Books from the Library of Leonard and Virginia Woolf. Brighton: Holleyman, 1975.

Crossland, Rachel. "Sharing the Moment's Discourse: Virginia Woolf, D. H. Lawrence and Albert Einstein in the Early Twentieth Century." DPhil thesis. U of Oxford, 2010.

Einstein, Albert. The Collected Papers of Albert Einstein: English Translation. Vol. 2. Trans. Anna Beck. Ed. John Stachel et al. Princeton: Princeton UP, 1989.

Engels, Friedrich. The Condition of the Working Class in England. Ed. David McLellan. Oxford: Oxford UP, 1993.

Gigerenzer, Gerd, et al. The Empire of Chance: How Probability Changed Science and Everyday Life. Cambridge: Cambridge UP, 1989.

Hayles, N. Katherine. Chaos Bound: Orderly Disorder in Contemporary Literature and Science. Ithaca: Cornell UP, 1990.

Le Bon, Gustave. The Crowd: A Study of the Popular Mind. London: Fisher Unwin, 1896.

MacCarthy, Desmond. Dedication. The Death of a Nobody. By Jules Romains. Trans. Desmond MacCarthy and Sydney Waterlow. London: Latimer, 1914. iii-vii.

McDougall, William. The Group Mind: A Sketch of the Principles of Collective Psychology with Some Attempt to Apply Them to the Interpretation of National Life and Character. Cambridge: Cambridge UP, 1920.

McLaurin, Allen. "Consciousness and Group Consciousness in Virginia Woolf." Virginia Woolf: A Centenary Perspective. Ed. Eric Warner. London: Macmillan, 1984. 28-40.

Maurer, Oscar. "Leslie Stephen and the Cornhill Magazine, 1871-82." The University of Texas Studies in English 32 (1953): 67-95.

Maxwell, James Clerk. "Molecules." Nature 8.204 (1873): 437-41. 
Moscovici, Serge. The Age of the Crowd: A Historical Treatise on Mass Psychology. Trans. J. C. Whitehouse. Cambridge: Cambridge UP, 1985.

Nicholls, Peter. Modernisms: A Literary Guide. 2nd ed. Basingstoke: Palgrave Macmillan, 2009.

Nye, Mary Jo. Molecular Reality: A Perspective on the Scientific Work of Jean Perrin. London: Macdonald, 1972.

Nye, Robert A. The Origins of Crowd Psychology: Gustave LeBon and the Crisis of Mass Democracy in the Third Republic. London: SAGE, 1975.

Parsons, Deborah L. Streetwalking the Metropolis: Women, the City, and Modernity. Oxford: Oxford UP, 2000.

Pearson, Karl. The Grammar of Science. 3rd ed. London: Black, 1911.

Perrin, Jean. Atoms. Trans. D. LL. Hammick. London: Constable, 1916.

---. Brownian Movement and Molecular Reality. Trans. F. Soddy. London: Taylor, 1910.

Porter, Theodore M. "A Statistical Survey of Gases: Maxwell's Social Physics." Historical Studies in the Physical Sciences 12.1 (1981): 77-116.

Rigden, John S. Einstein 1905: The Standard of Greatness. Cambridge, Massachusetts: Harvard UP, 2005.

Ruskin, John. The Works of John Ruskin. Vol. 19. Ed. E. T. Cook and Alexander Wedderburn. London: Allen, 1905.

Schadschneider, Andreas. "I'm a Football Fan... Get Me Out of Here." Physics World $23.7(2010): 21-5$.

Shenstone, W. A. “About Solutions.” The Cornhill Magazine ns 20.117 (1906): 32334.

---. "Matter, Motion, and Molecules." The Cornhill Magazine ns 20.115 (1906): 6374.

Simmel, Georg. The Sociology of Georg Simmel. Trans. and ed. Kurt H. Wolff. Glencoe, Illinois: Free Press, 1950.

Tarde, Gabriel. On Communication and Social Influence: Selected Papers. Trans. N. Claire Ellis, Priscilla P. Clark and Terry N. Clark. Ed. Terry N. Clark. Chicago: U of Chicago P, 1969.

Tratner, Michael. Modernism and Mass Politics: Joyce, Woolf, Eliot, Yeats. Stanford: Stanford UP, 1995.

Trotter, W. Instincts of the Herd in Peace and War. London: Fisher Unwin, 1916.

Woolf, L. S. "The Inhuman Herd.” The New Statesman 7.170 (1916): 327-8.

Woolf, Virginia. The Diary of Virginia Woolf. 5 vols. Ed. Anne Olivier Bell and Andrew McNeillie. London: Hogarth, 1977-84.

---. The Essays of Virginia Woolf. Vol. 5. Ed. Stuart N. Clarke. London: Hogarth, 2009.

---. Flush: A Biography. Ed. Alison Light. London: Penguin, 2000.

---. Moments of Being: Autobiographical Writings. Ed. Jeanne Schulkind. Rev. ed. London: Pimlico, 2002.

---. Mrs Dalloway. Ed. Stella McNichol. London: Penguin, 1992.

---. Night and Day. Ed. Julia Briggs. London: Penguin, 1992.

---. Orlando: A Biography. Ed. Brenda Lyons. London: Penguin, 1993.

---. The Voyage Out. Ed. Jane Wheare. London: Penguin, 1992.

---. The Waves. Ed. Kate Flint. London: Penguin, 1992.

---. The Years. Ed. Jeri Johnson. London: Penguin, 1998. 